\title{
The Review of Experiments on the Ultimatum Game under Competitive Conditions
}

\author{
Xinqing Luo* \\ International School of Business \\ Beijing International Studies University \\ Beijing, China \\ E-mail:luoxinqing@126.com
}

\author{
Baoshan Zhang \\ International School of Business \\ He Jun Consulting Group \\ Beijing, China \\ E-mail:zhangbaoshan126@126.com
}

\author{
Fajia Chen \\ School of English Education \\ Beijing International Studies University \\ Beijing, China \\ E-mail:chenfajia@bisu.edu.cn
}

\begin{abstract}
The ultimatum game is one of the most basic models in the field of experimental economics. When competitive factors are considered in the ultimatum game, its development from two-person players to multiplayers is an important expansion of the model. This paper systematically combs through relevant literature on the ultimatum game and summarizes and revie ws theoretical models from various perspectives, namely, the role of competition in the ultimatum game, competition between experimental participants, size of the total amount under competition, introduction of competition framework, and competition between multiplayers. This paper also offers suggestions and directions for further theoretical research in other possible fields of the ultimatum game.
\end{abstract}

Keywords-ultimatum game; fairness preference; competition

\section{INTRODUCTION}

Traditional economics assumes that people have pure selfinterest preference and are completely selfish, but do not pay attention to fairness, be it fairness in the motivation for justice or fairness in income allocation. However, modern research in emerging behavioral economics has confirmed that that is not the case. In many cases, fairness preference will affect people's behavior, and personal motivation and behavior often have a close contact with fairness preference (Fehr Schmidt, 1999[19]; FerhrFalk, 2003[17]; Camerer, 2006[10]).

Fairness preference has a major impact on the decisionmaking behavior, but Feher \& Schmidt (1999)[19] study shows that preferences are not necessarily fair and may lead to "unfair practices", which means that the decision-making behavior depends not only on the type of behavior preferences, but also on the interactive economic environment and prediction of others' preference. Experiments and in-depth discussions on the standard ultimatum game were conducted. However, the reality is fraught with competition, and while this competitive environment plays a positive role in promoting the development of society, it also causes some problems, such as the issue of fairness. In the realistic society, everyone has an appeal for fairness, and fairness in competition becomes a focus of attention, and therefore studies began to rise to fit the reality of competition ultimatum game. Studying fairness preference in the competitive ultimatum game not only enriches and develops ultimatum game experiments, but also provides guidance for equity issues existing in the real world.

More than thirty years after the publication of the first ultimatum bargaining experiment, studies of a variety of expansions of the standard ultimatum game give people an indepth understanding of fairness preference under different conditions. Guth et al. (2014)[26] reviewed and summarized thirty years of development of the ultimatum game, but the introduction of competition in the ultimatum game was not discussed in depth. Compared with studies abroad, domestic research mainly focuses on the standard ultimatum game itself and its related literature, its different models and application in other disciplines (Guang-xing Wei, 2006[39]; Wei Qian, 2010[38]; Zhi-qiang Dong, 2011[16]; Wan-li Zhang, 2014[40]; Yefeng Chen,2014[11], etc.), while there are not many research-related experiments (Yefeng Chen et al., (2011)[12]. Currently, little is done in the research on the ultimatum game under competitive conditions.

The remainder of the paper is organized as follows. The second part reviews the experimental results of the standard ultimatum game; the third part deals systematically with various sorts of ultimatum game experiments under competitive conditions and summarizes them respectively; the fourth part describes and evaluate existing theoretical models of the ultimatum game where competition is introduced; the fifth part discusses fairness and efficiency in a competitive situation. The sixth part serves as a brief review of the existing researches, offers suggestions and directions for further theoretical research in other possible fields .

The paper supported by the National Social Science Fund of China (Grant No. 12CJL007) and the Practice Base for Experimental Economics of BISU. 


\section{The Introduction of COMPETITIVE FACTORS IN THE} UltimATUM GAME

\section{A. Standard ultimatum game experiments}

The ultimatum game was originally designed by Guth et al. (1982)[22], and then repeated by Camerer\&Thaler (1995)[13], Roth (1995)[35], etc. for many times. Because of its simple structure and convenience to operate and repeat, the experiment has sufficient persuasion, and there are a lot of expansion-type dictator game (Roth, 1995 [35] ; Camerer, 2003[14]), providing future researchers with good tools. In this bilateral ultimatum game experiment, the participants are divided into two groups as responders and proposers to bargain over a sum of money $\boldsymbol{P}$. The proposer can make exactly one offer to the responder, which the latter can accept or reject. If the offer is rejected, both players earn zero. If the offer is accepted, each player earns the amount that was proposed by the proposer.

According to the traditional economic assumption that respondents would not object to any offer greater than zero, so proposers will offer respondents only very little amount(close to zero).But hundreds of experiments conducted by different economists in different countries at different time among different people consistently show that an offer will always be accepted if it covers around $40-50 \%$ of the pie in the standard version of the game.;and when the proposer's offer is below $20 \%$ of the pie, the possibility of rejection will be up to 40 $60 \%$;responders'rejection rates decrease with greater offers, and the results are almost free from the impact of the amount of money, which is clearly different from the ultimatum game results predicted in purely self-interested preferences . A more reasonable explanation is that people have a preference for fair, and responders will resist this injust offer. (Güth et al, 1982[22]; Güth and Tietz, 1990[27]; Roth, 1995[35]).

It has proved that people also have fairness preference in addition to self-interest preference through a series of ultimatum game experiments in recent years. Fairness, however, is not a concept that is devoid of context. The influence of fair preference to people's behavior is different while people's understanding of the fairness preference is different or restricted by their conditions. Therefore, it is worth studying what the fair preference of people is in the competitive environment and what impact it will have on people's behavior. We will examine changes in people's fairness preferences under conditions of competition through the introduction of competitive factors in the ultimatum game as follows.

\section{B. Competitive factors in the ultimatum game}

Introducing competition in the ultimatum game experiments is produced by simulating real competition under different conditions.Through the summary, we will introduce the main competition divided into the following four ways: (1)the competition among participants; (2)the competition for the pie of money;(3)the introduction of competitive frame; (4)the competition generated from multiplayer game, including proposer competition, responder competition and dummy players competition.

\section{1) The Competition among Participants}

Güth and Tietz (1985[23], 1986[25]) distributeroles between proposers $\mathrm{X}$ and responders $\mathrm{Y}$ (see also Hoffman and Spitzer, 1985) by auction instead of offers, finding the prices proposers $X$ put forward in auction is twice high as those of responders Y,hardly any equal split but splits of pie $\mathrm{p}$ in the range of $y=\boldsymbol{p} / 3$.Hoffman et al. (1994) [29]distributed rolesof proposers to paticipants who perform better in the assigned quiz and found that the proposers, who had been the winners in the quiz, put forward lower prices reduced by $10 \%$, i.e, proposers had less willing to persure equal sharing of $\boldsymbol{p}$. However,the rates of rejection rose because the right proposers won seemed not admitted by the side of responders and triggered a self-serving bias of them. Schotter et al.(1996)[36]also made a similar experiment by conducting a set of two-stage survival ultimatum and dictatorship games in which participants 'survived' stage 1 and proceed to stage 2 only when their eranings were in the first half among all the players. ${ }^{1}$ Results showed that the proposers' offer in the ultimatum game also reduced by about $10 \%$ under the competitive pressure to 'survive', and responders were willing to accept this lower offer because of the above rule, rather than using the minimum offer expected.

Schotter et al. (1996)[36] raised such a question whether it is feasible to provide an excuse to selfish behavior under the competitive pressure for survival. In the absence of pressure to survive, it is likely to be considered unfair for the proposers' lower offers and the responders would refuse the offers in most cases. However, under the pressure to survive, it may be reasonable for the proposers' lower offers since the proposers do not think they are selfish even if presenting with less offers because of the qualifications they acquired in the competition, and the responders also recognized it as the environment has changed. So they think fairness is not an absolute concept but a relative concept under different circumstances and the competition has an important influence on the fairness.

\section{2) The Competition for the Pie of Money}

Bradley J. Ruffle (1998) [7]introduced the competition of pie to the ultimatum game experiments and dictator game experiments which are conducted in two stages.During the first stage, the responders earned part of the pie through the competition of their knowledge and skills and toss of coins; in the second stage, the proposers and the responders performed ultimatum game experiments and dictator game experiments based on the total offers responders obtained in the first stage. Experimental results show that the average offer from the responders in the dictator experiments who competed to earn accounted for about $45 \%$ of the pie while the average offer from the responders who were willing to accept the proposers' offers was $33.7 \%$.In the ultimatum game experiment the proposers' average offers were nearly half of the pie (approximately 48.8\%), and responders' acceptance rate also increased to $45 \%$.

\footnotetext{
${ }^{1}$ 'Survival' means that the participants could beenough to continue to participate in the experiment, because if the participant does not qualify to participate in the experiment, there is no income, if received, he can get more income in subsequent experiments.
} 
At the same time, by comparing the results of the ultimatum game and the dictator game, we found that proposers' offer was by no means strategically motivated. All four dictator game experiment results showed that dictators' offers were more than half of those proposers' in ultimatum game. More exactly, dictators' offers for the responders who obtained more and less part of the pie constituted 92.2\%, 53.8\% respectively.In ultimatum game, the responders' rejection was not a threat for the proposers to raise their offers, that is to say, the offers from the proposers to the responders who obtained more sum of the pie were driven by the will for fairness, rather than strategic motivations.

\section{3) The Introduction of Competitive Frame}

Buhren et al. (2012)[42]introduced a competitive frame in mini-ultimatum games utilizing chess puzzles, and they use chess players as their participants.The experiment found that, in the competitive frame,participants allowed the maximization of their rivals' income and accepted low offers . This means that participants pursuit fairness will be less in a competitive environment. Observing the similar competition in real situation, procurement manager may allow contractors to maximize their own interests rather than punishing them because of their upstream-downstream relationship; baseball players in the competition may accept lower wage (Telser, 1995)[37], and therefore a highly-competitive environment has a direct impact on the bargaining and accepting a lower offer and particitants' fairness preferences play a even smaller role.

4) The Competition Generated from Multiplayer Game

In a multiplayer game, if there are more than one competitive relationship among proposers, responders or the dummy players,it will produce an unusual effect on the result of the game and fairness preferences.

a) Proposers' competition (one responder, at least two proposers)

For the proposers' competition, it is divided into two cases, one is the symmetric proposers' competition,and the other is asymmetric proposers' competition. ${ }^{1}$

The symmetric proposers' competition first appeared in the "market game" Roth et al. (1991)[34] conducted in which nine proposers provided offers to a single responder simultaneously. The responder accepted the largest one of all the offers. The proposers' offers were scattered in the first round, but much higher than offers in the standard ultimatum game, most of which were more than half of the whole pie. And the largest offer was really high, about $95 \%$ of the pie.However, the proposers almost offered the entire pie during the second round. Fischbacher et al. (2009) [18]conducted the experiments between two symmetric proposers and one responder. The result showed that the average offer from the proposers was approximately $70 \%$ of the pie,which was lower than Rothet et al. (1991)[34], and did not appear to shrink rapidly. Because for the latter ones, the more proposers from

\footnotetext{
${ }^{1}$ Symmetric and asymmetric proposers competition, mainly refers to whether the pie of proposers to compete equally separated, if the pie is equal, itcalled symmetrical proposers competition; If not equal, big and small, is asymmetric proposer competition.
}

the former participated in the symmetric competiton, the more intense the degree of competition was.

Another version of the ultimatum game with symmetric proposers' competition was examined by Abbink et al. (2003)[1]. Three proposers with equal cake sizes made offers to a single responder sequentially. Similar to the standard ultimatum game, subgame perfect equilibrium predicts that the responder should receive very little: no more than the smallest unit of money at three times. However, results in the third stage closely resembled standard ultimatum games, with offers in the prior stages often exceeding half the cake.

Asymmetric proposers' competition mainly conducted by Caleb A. Cox (2012)[9]. In this experiment he studied a threeplayer ultimatum game in which two proposers with unequal amounts of money simultaneously submit offers to one responder, who may accept at most one offer. He compared the predictions of inequity aversion, advantage seeking, and self-interest. Unlike previously studied cases of symmetric proposers' competition, the predictions of these models do not coincide in the asymmetric case. The results showed that responders in this experiment sometimes accepted the smaller offer, which meant the degree of asymmetry between proposers affected the responder's behaviors. The results furthersuggested advantage-seeking preferences among heterogeneous responders occurred more frequently.

\section{b) Responders' competition (one proposer, at least two responders)}

GuthW. et al (1997)[21] first introduced the responders' competition to the ultimatum game experiments:one proposer submitted offers to five responders. Brit Grosskopf (2003)[8] conducted experiments with competition between three responders who were offered by only one proposer. The deal was made as long as one of the three responders accepted the offer from the proposer. The result of the game showed a steady reduction in the proposer's offer, which was less than the one in the standard ultimatum game. And the rejection rate of the responders is lower than the one in the standard ultimatum game as well. Fischbacher et al. (2009)[18] discussed the impact varying extent of the responders' competition have on the bargaining . The experiments studied the situation of competiton when the proposer offered the two and five responders. It found that as competition intensifies (responders increased from two to five),the willingness of refusion from responders is further reduced. This shows that the extent of competition has an important impact on people's willingness to pursue fairness.

\section{c) The additional dummy player}

Compared to proposers' and responders' competition, such three-person games increased the variety of players' types by increasing the additional dummy player, forming a potential competition. In this experiment, the proposer $\mathrm{X}$ divided a given pie $\mathrm{p}(>0)$ by choosing $(\mathrm{x}, \mathrm{y}, \mathrm{z})$ with $\mathrm{x}, \mathrm{y}, \mathrm{z} \geq 0$ and $\mathrm{x}+\mathrm{y}$ $+\mathrm{z}=\mathrm{p}$, and distributed the $\mathrm{y}$ to the responder $\mathrm{Y}$, the $\mathrm{z}$ to the dummy player $\mathrm{Z}$,. The responder $\mathrm{Y}$ could reject the y so that the three players would get no income at all, but also could accept the $\mathrm{y}$ for the dummy player $\mathrm{Z}$. These experiments did not find a tendency for (active)responders to reject due to the payoffs of the passive player, suggesting that passive players 
may not be considered as members of the relevant reference group(see Guth\& van Damme,1998;[20]Kagel\& Wolfe ,2001;[30]Okada \&Riedl, 2005[33]). In addition to proposer $\mathrm{X}$ and responder $\mathrm{Y}$, there is a dummy player $\mathrm{Z}$ without any direct influence on the allocation of resources.However, a striking result was that both proposer $\mathrm{X}$ and responder $\mathrm{Y}$ seemed to give much care about the dummy player Z(see Bolton and Ockenfels, 1998[6], who focus on this observation), at least some concerns(Güth et al., 2007).[24]

\section{CONCLUSIONS}

According to games from the standard ultimatum to games introduced competition in the various expansion type, especially multiplayer ultimatum game, the proposers' competition, the responders' competition and the dummy players' competition enable us to have a deeper understanding of fairness preference.But the existing studies also have some problems need to be explored further.

First of all, the introduction of competition to the ultimatum game makes the game environment more complicated and it becomes quiet necessary to further study various competition cases segmentally. For example, changes in the extent of competition will have a greater impact on player'preferences fairness. Fischbacher et al. (2009)[18] discussed the impact varying extent of the responders' competition on the bargaining. The experiments studied the situation of competiton when the proposer offered the two and five responders. It found that as competition intensifies (responders increased from two to five),the willingness of refusion from responders is further reduced. Similarly, by comparing the experiment results between 9 proposers (Roth et al., (1991)[34] and 2 proposers (Fiscbacher et al. 2009)[18],we found that the more the number of the proposers, the more the proposers's bid closer to the total amount.

So from the above experiments we found that: different extent of competition makes it different for people to pursuit fairness whether it is proposers' competition or responders' competition. There is a clear trend: when the number of competitors gradually increased, people's willingness to pursue fairness declined gradually. Meanwhile, Fehr \& Schmidt(1999)[19] have found that the introduction of inequity aversion hardly affects the subgame perfect equilibrium outcome whether it is proposers' competition or responders' competition as the competition intensified. It does not matter for the outcome whether there are many or only a few subjects who received strong inequity aversions. In a highly competitive environment, individual participants can not stop the unfairness, making the inequity aversion factor no longer important in the equilibrium. So at what level of competition can people's unjust have an impact on fair results? To what extent of competition is it fair to the proposer and the respondent? These problems need further research and discussion. Besides, we can also compare the difference between the effect resulted from the proposers and the responders.

In addition, with the introduction of competition, the results of the game become more uncertain. In the introduction of dummy players, the experimental results ofGuth\& Van
Damme (1998)[20], kagel\& Wolfe (2001)[30] and Okada \&Riedl (2005)[33] found that responder Y did not take into account the "dummy" player $\mathrm{Z}$ to reject an offer. There is no direct impact on the outcome distribution for the dummy player are not considered,However, a striking result was that not only proposer $\mathrm{X}$ but also responder $\mathrm{Y}$ seemed to care much about the dummy player (see Bolton andOckenfels, 1998[5], who focus on this observation). In contrast, a later newspaper experiment revealed at least some concernsfor the dummy player Z (Güth et al., 2007)[24]. So the impact of the dummy player on the fair consideration still needs to be verified.

Moreover, with the introduction of competition, the results of the ultimatum game under competitive conditions questioned the existing economic model prediction. For example, when FS model and BO model introduce the "dumb" competitors, in the ultimatum game of two people, BO model adheres to the zero-rejection principle for all positive bid, or FS model predicts all offers for which a rejection creates greater disadvantageous inequality than the disadvantageous inequality associated with accepting the offer.Many scholars pointed out that Bolton, Ockenfels, Fehr and Schmidt recognize that intentionality plays some roles in their models (in particular, see the experiments reported in Blount, 1995[4]; Charness, 2002[15]; and Kagel et al., 1996[31]). But they argue that intentionality and negative reciprocity and other factors only show the secondary effort which can't explain the bulk of the data. But Kagel et al. (2001) found that it was not the case in the three people's game. The function of intentionality and negative reciprocity is far beyond the model predictions. This shows thatexisting equity model does not fully capture the changes in people's behaviorunder conditions of competition.With the introduction of competition, the driving factor behind the behavior of participants may also be changed. Under competitive conditions, are there any main driving factors behind participants' behaviors, such as unfair dislikes, motivations or negative reciprocity? More research is needed to verify it.

Furthermore, Kagel et al. (2001) [30]also found that the FS model and the BO model has a certain framing effect, because respondents refused a positive bid which did not show their disgust for inequity. So the simple and direct expansion based on the original model could not explain a new game. This shows that prediction of the existing model of ultimatum game under competitive conditions also need further verification. With the introduction of competition, the model should consider adding more factors or combinations between models in order to adapt to the "new" ultimatum game experiment preferably under the competitive situation.

As one of the countries with the larger gap between the rich and the poor, the problem of social equity distribution of China has become the prominent contradiction in the economic construction of our country. Referring to foreign research results and combining with the characteristics of China, establishing a theoretical model which fits our specific socio-economic conditions is of significance for the guidance of thestaffincentive mechanism, corporate governance, social distribution system and so on. But the domestic competition ultimatum game experiments rarely, Liu Shuai (2015)[32] was 
introduced responder competition into the ultimatum game based on the Chinese context.

It is found that the introduction of responder competition will reduce people preferences for the degree of fair. With the continuation of the competition time, people in the competitive environment tend to have a higher acceptance for unfair price. In the Chinese context, people's fairness preference is high and stable, and the competitive leading party will not reduce its bid without limit.Thus, in the context of China, people's fairness preferences in the competition is a problem worthy of in-depth study.

\section{REFERENCES}

[1] Abbink, K., Darziv, R., Gilula, Z., Goren, H., Irlenbusch, B., Keren, A., Rockenbach, B., Sadrieh, A., Selten, R., Zamir, S., "The Fisherman's problem: Exploring the tension between cooperative and non-cooperative concepts in a simple game” ,Journal of Economic Psychology, 2003(24), 425-445.

[2] Bellemare, C., Kröger, S., van Soest, A., "Measuring inequity aversion in a heterogeneous population using experimental decisions and subjective probabilities”,Econometrica, 2008, 76, 815-839.

[3] Bellemare, C., Kröger, S., van Soest, A., "Preferences, intentions, and expectations violations: a large-scale experiment with a representative subject pool”,Journal of economic behavior\& organization, 2011, 78, 349 $-365$

[4] Blount, When Social Outcomes aren't fair: the Effect of Causal Attributions on Preferences, Organizational Behaviors and Human Decision Process, 1995 (LXIII):131 144.

[5] Bolton, G.E., Ockenfels, A., "Strategy and equity: an ERC-analysis of the Güth-van Damme game”, Journal of Mathematical Psychology, 1998, 42, 215-226.

[6] Bolton, G.E, Ockenfels, A., "ERC: a theory of equity, reciprocity and competition”,American Economic Review, 2000,90, 166-193.

[7] Bradley J. Ruffle, "More is better, but fair is fair: tipping in dictator and ultimatum games",Games and Economic Behavior, 1998, 23, 247-265.

[8] Brit Grosskopf, "Reinforcement and directional learning in the ultimatum game with responder competition”, Experimental Economics,2003, 6, 141-158.

[9] Caleb A.Cox, "Inequity aversion and advantage seeking with asymmetric competition," Journal of econo mic behavior\& organization,2012, 86,121136.

[10] Camerer, Colin F.,Behavioral game theory: experiments in strategic interaction. In:Russell sage foundation,simplified Chinese version, China renmin university press,2006, 2,41-75.

[11] Chen Yefeng, “The Ultimatum Game and Fairness”, South China Journal of Economics,2014,6,81-86.(In Chinese)

[12] Chen Yefeng, Zhou Yean and Song Zifeng, "Inequality aversion or reciprocity?--an investigation of two kinds of fairness in the ultimatum game”, Economic Research Journal, 2011,6,31-44. (In Chinese)

[13] Camerer, C. and Thaler, R. "Ultimatums, Dictators and Manners." Journal ofEconomic Perspectives, 1995, 9, pp.209-219.

[14] Camerer, Colin F. "Behavioural studies of strategic thinking in games". Trends in Cognitive Sciences, Vol. 7, No. 5 May 2003, 225-231.

[15] Chaness G Rabin,M.Understanding social preferenccs with simple tests[J].Quarterly journal of Economics.2002(117)817-869.

[16] Dong Zhiqiang, "Why do we prefer fairness: an explanation based on evolutionary view”, Economic Research Journal,2011,8,65-77.(In Chinese)

[17] Falk, A., Fehr, E., Fischbacher, U. "On the nature of fair behavior", Economic Inquiry, 2003, 41, 20-26.

[18] Fischbacher, U., Fong, C., Fehr, E., "Fairness, errors and the power of competition”,Journal of economic behavior\& organization,2009,72, 527545.

[19] Fehr,E.and Schmidt,K, “A Theory of Fairness,Competition,and Cooperation”, Quarterly Journal of Economics,1999,114,pp. 817-868.
[20] Güth, W., Damme, E.V., "Information strategic behavior and fairness in ultimatum bargaining: an experimental study", Journal of Mathematical Psychology, 1998, 42 (2-3), 227-247.

[21] Guth W., Marchand N., Rulliere J.L., "On the Reliability of Reciprocal Fairness: an Experimental Study”, Working Paper, Humboldt University of Berlin, 1997.

[22] Güth, W., Sch mittberger, R., Schwarze, B., “An experimental analysis of ultimatum bargaining”, Journal of economic behavior \& organization, 1982, 3, 367-388.

[23] Güth, W., Tietz, R., "Strategic power versus distributive justice - an experimental analysis of ultimatum bargaining”, In: Brandstätter, H., Kirchler, E. (Eds.), Economic Psychology Proceedings of the 10th IAREP Annual Colloquium. Linz, pp. 1985, 129-137.

[24] Güth, W., Schmidt, C., Sutter, M., "Bargaining outside the lab - a newspaper experiment of a three-person ultimatum game", Economic Journal, 2007, 117, 449-469.

[25] Güth, W., Tietz, R., “Auctioning ultimatu mbarga ining positions - how to act if rational decisions are unacceptable?” In: Scholz, R.W. (Ed.), Current Issues in West German Decision Research. P. Lang Publisher, Frankfurt, pp. 1986, 173-185.

[26] Güth, W,Kocher, "More than thirty years of ultimatum bargaining experiments: Motives, variations, and a survey of the recent literature”, Journal of Economic Behavior \& Organization , 2014 , 108 (C) :396-409

[27] Güth , R Tietz.”Ultimatum bargaining behavior : A survey and comparisonof experimental results.Journal of EconomicPsychology,1990,11(3): :417-449

[28] Hoffman, E., Spitzer, M.L., Entitlements, "Rights and fairness: an experimental examination of subjects' concepts on distributive justice, J. Legal Stud., 1985, 14, 259-297.

[29] Hoffman.E.McCabe,KIL Shachat,K \& Smith,V.L .Prefcrenccs,property rights andanony mity in bargaining games.Games and Economic Behavior,1994,7,346-380

[30] Kagel.J.H., Wolfe, K.W., “Tests of fairness models based on equity considerations in a three-person ultimatum game”, Experimental Economics, 2001, 4 (3), 203-219.

[31] Kagel.J.H”Fairness in Ultimatum Games with Asymmetric Information and Asymmetric Payoffs"[J]. Games and Economic Behavior . 1996 (1) $100-110$

[32] Liu shuai, "Competitive factors in fluence Fairness - experimental analysis based on Chinese context”, working paper, Beijing international studies university. (In Chinese)

[33] Okada, A., Riedl, A., "Inefficiency and social exclusion in a coalition formation game: experimental evidence”, Games and Economic Behavior, 2005, 50 (2), 278-311.

[34] Roth, A., Prasnikar, V., Okuno-Fujiwara, M., Zamir, S., “Bargain ing and market behavior in Jerusalem, Ljubljana, Pittsburg, and Tokyo: an experimentalstudy”,American Economic Review, 1991, 81, 1068-1095

[35] Roth AE,Erev I. "Learning in extensive-form games: experimental data and simple dynamic models in the intermediate term.Games and Economic Behavior" . 1995

[36] Schotter, Andrew, Avi Weiss, and In igo Zapater, "Fairness and survival in ultimatum and dictatorship games", Journal of Economic Behavior and Organization, 1996, 31, 37-56.

[37] Telser, L.G., “The ultimatum game and the law of demand”, Economic Journal, 1995, 105, 1519-1523.

[38] Wei Qian, “Economics of incorporating fairness: theory and evidence” , Economic Research Journal,2010,9,137-148.(In Chinese)

[39] Wei Guang xing, "A survey of game experiments andtheoretical models on fairness preference", Journal of Quantitative \& Technical Economics,2006,8,52-160. (In Chinese)

[40] Wan-li Zhang,"Research Review of Ultimatum Game”,Journal of WeifangEngineering Vocational College, 2014, 2,30-33.(In Chinese)

[41] Bühren, C., Frank, B., Krabel, S., Werner, A., "Decision-making in competitive framings - strategic behavior of chess players in miniultimatum gamechess puzzles" ,Economic. Letter, 2011,115, 356-358. 